\title{
Thyroid dysfunction in patients of metabolic syndrome: A study from a tertiary care center in India
}

\author{
Ritu Gupta', Akhil K Vijayan², Sushma Choudhary ${ }^{3}$ \\ ${ }^{1}$ Professor and Head, ${ }^{2}$ Postgraduate Resident, ${ }^{3}$ Assistant Professor, Department of Medicine, \\ Netaji Subhash Chandra Bose Medical College, Jabalpur, Madhya Pradesh, India
}

Background: Metabolic syndrome is characterized by hypertension, dyslipidemia, central obesity, glucose intolerance, insulin resistance. Thyroid hormone acts as general pacemaker, accelerating metabolic process and may be associated with metabolic syndrome. There is no information available in literature regarding the prevalence and association of thyroid dysfunction in metabolic syndrome in this central region of the country. Aims and Objective: To estimate the prevalence of thyroid dysfunction in patients of metabolic syndrome. Materials and Methods: It is a duration based prospective cross sectional study including 200 patients of metabolic syndrome. A detailed history, clinical examination and relevant investigations including serum Free T4 (FT4), Free T3 (FT3), Thyroid Stimulating Hormone (TSH) were done. Range, frequencies, percentage, mean, standard deviation and $P$ value were calculated. $P$ value of $<0.05$ was taken as significant. Results: Prevalence of thyroid dysfunction in metabolic syndrome patients was $28.5 \%$. Prevalence of subclinical and overt hypothyroidism was $18.5 \%$ and $8.5 \%$ respectively. In patients with both metabolic syndrome and thyroid dysfunction, most common components associated are diabetes mellitus and hypertriglyceridemia. Conclusion: Thyroid dysfunction is significantly common in metabolic syndrome patients. It should be aggressively detected and treated in these patients for better outcome.

Key words: Diabetes mellitus; Hyperthyroidism; Hypothyroidism; Metabolic syndrome; Subclinical hypothyroidism; Thyroid dysfunction
Access this article online

Website:

http://nepjol.info/index.php/AJMS

DOI: $10.3126 /$ ajms.v12i10.38313

E-ISSN: 2091-0576

P-ISSN: $2467-9100$

Copyright (c) 2021 Asian Journal of Medical Sciences

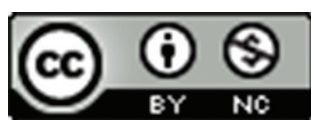

This work is licensed under a Creative Commons Attribution-NonCommercial 4.0 International License.

\section{INTRODUCTION}

Hypertension, dyslipidemia, central obesity, glucose intolerance, and insulin resistance characterize metabolic syndrome. It is also known as -Deadly quartetl, insulin resistance syndrome, syndrome X, Beer belly syndrome, dysmetabolic syndrome. ${ }^{1,2}$ Insulin resistance is the central pathophysiology behind this condition. ${ }^{3}$ Obesity, insulin resistance, physical inactivity; advanced age and hormonal imbalance are underlying risk factor for the development of the syndrome.

Thyroid hormones have very important effects and influence on the function of most organs. Thyroid hormones act as general pacemaker, accelerating metabolic process and may be associated with metabolic syndrome. Thyroid dysfunction and metabolic syndrome are associated with increased risk of atherosclerosis, cerebrovascular disease, cardiovascular disease, Non-alcoholic fatty liver disease (NAFLD).

Little is known about the relationship between Thyroid Dysfunction and Metabolic Syndrome. Only few studies have been performed. In a cross sectional study in 220 metabolic syndrome patients, subclinical hypothyroidism was prevalent in $16.4 \%$ of metabolic syndrome patients. ${ }^{4}$ In another study, it was found that metabolic syndrome was prevalent in thyroid dysfunction patients. ${ }^{5}$ The study done by Lin St et al found that lower free thyroxin level are associated with metabolic syndrome in Chinese 
population. ${ }^{6}$ There is no information available in literature regarding this association in this part of the country. Therefore, this study is done to estimate the prevalence of thyroid dysfunction in patients of metabolic syndrome.

\section{Aims and Objective}

To estimate the prevalence of thyroid dysfunction in patients of metabolic syndrome.

\section{MATERIALS AND METHODS}

This cross-sectional study was conducted at the outpatient and inpatient of General Medicine department of Netaji Subhash Chandra Bose Medical College Jabalpur Madhya Pradesh from First January 2019 to 30 ${ }^{\text {th }}$ September 2020. The study was pre-approved by the Institutional Ethics Committee (IEC) for the final permission. After obtaining the permission of IEC the study was conducted. Two hundred patients with features of metabolic syndrome according to International Diabetes Federation criteria $2005^{7}$ of age group 20-70 years were included in the study. Patients with primary thyroid disorder, irradiation of thyroid gland, thyroidectomy or thyroid surgeries, on drugs like anti-thyroid drugs, drugs that alter thyroid functions, lipids such as statins, lithium, amiodarone, oral contraceptive pills, steroid; with liver disorders; with renal disorders, in congestive cardiac failure, pregnant women and those who are taking iodized salt were excluded from the study. Proper informed consent was taken before including the patients. A detailed history and clinical examination was done. Investigations including complete blood count, liver function test, renal function test, fasting blood sugar, fasting lipid profile, ultrasonography scan of abdomen, ultrasonography scan neck, serum FT4, FT3, TSH were done. Metabolic syndrome patients were considered to have thyroid dysfunction if patients thyroid hormones level fell outside the reference range free T3 (0.31-0.65 ng/dl), free T4 (0.7-1.6 ng/dl) and TSH level $(0.25-5 \mathrm{mIU} / \mathrm{L}))$. Patients were said to be euthyroid if all thyroid hormone levels fell within reference range. Overt hypothyroidism was defined as TSH $>5 \mathrm{mIU} / \mathrm{L}$, free T3 $<0.31 \mathrm{ng} / \mathrm{dl}$ and free $\mathrm{T} 4<0.7 \mathrm{ng} / \mathrm{dl}$. Subclinical hypothyroidism was considered if TSH $>5 \mathrm{mIU} / \mathrm{L}$ and free T3 and free T4 within reference range. Subclinical hyperthyroidism was defined as TSH $<0.25 \mathrm{mIU} / \mathrm{L}$ and free $\mathrm{T} 3$ and free $\mathrm{T} 4$ within reference range. The information collected regarding all the selected cases were recorded in a master chart.

\section{STATISTICAL ANALYSIS}

Statistical analysis was carried out for 200 patients with metabolic syndrome. The association was analyzed using frequency analysis, percentage analysis and Chi- square test. $\mathrm{P}$ value of $<0.05$ was taken as significant. Microsoft Excel 2013 and SPSS (Statistical Package for Social Sciences) Version 22.0 software was used for data entry and analysis.

\section{RESULTS}

Out of 200 patients included in the study, 118 (59\%) were female and $82(41 \%)$ were male. Most of patients fall in age group 36-55 years. Age of female ranged from 25 to 87 years with mean age 51.53 and Standard Deviation 10.94. Age of male ranged from 27 to 80 with mean 51.59 and Standard Deviation 10.51 (Table 1).

According to metabolic syndrome parameters, 8 (4\%) fulfilled all metabolic syndrome parameters criteria, $67(33.5 \%)$ fulfilled four criteria and rest $125(62.5 \%)$ subjects fulfilled three criteria. Statistical analysis with Chi square test does not reveal any significant trend in distribution with $\mathrm{P}>0.05(\mathrm{P}=0.618)$. As waist circumference is absolute criteria to define metabolic syndrome, it was present in all subjects. Other than waist circumference, diabetes was the most common among metabolic syndrome patients (68\% of total subjects). Hypertriglyceridemia contributes $67 \%$ of total subjects and hypertension and low HDL level contributes 40.5\% and $29 \%$ respectively. One hundred and forty three $(71.5 \%)$ patients found to be euthyroid and 17(8.5\%) patients were hypothyroid. 37 (18.5\%) patients had sub clinical hypothyroidism. Only one patient had overt hyperthyroid and 2 patient had sub-clinical hyperthyroidism in this study. Overall thyroid dysfunction is more common in females than males (Table 2).

Statistical analysis with Chi Square does not reveal any significant trend in distribution with $\mathrm{P}>0.05(\mathrm{P}=0.170)$. Based on the metabolic syndrome criteria, out of 125 patients who fulfilled three of five criteria, 28 had thyroid dysfunction (16- subclinical hypothyroidism, 9- Overt hypothyroidism, 2-subclinical hyperthyroidism, 1- overt hyperthyroidism). Out of 67 subjects who had 4 of 5 criteria, 18 had subclinical hypothyroidism and 8 had overt hypothyroidism. Out of 8 subjects who fulfill all criteria, 3 had subclinical hypothyroidism (Table 3).

Statistical analysis with Chi square test does not reveal any significant trend in distribution with $\mathrm{P}>0.05(\mathrm{P}=0.166)$

\section{DISCUSSION}

In our study we selected 200 patients with metabolic syndrome from outpatient and inpatient division of department of Medicine. In this study, disease was 


\begin{tabular}{|c|c|c|c|c|c|c|}
\hline \multirow[t]{3}{*}{ Age } & \multicolumn{4}{|c|}{ Sex } & \multirow{2}{*}{\multicolumn{2}{|c|}{ Total }} \\
\hline & & Female & & Male & & \\
\hline & \multicolumn{2}{|c|}{ Count Percentage } & \multicolumn{2}{|c|}{ Count Percentage } & \multicolumn{2}{|c|}{ Count Percentag } \\
\hline $\begin{array}{l}25-35 \\
\text { yrs }\end{array}$ & 07 & 05.9 & 05 & 06.1 & 12 & 06.0 \\
\hline $\begin{array}{l}36-45 \\
\text { yrs }\end{array}$ & 30 & 25.4 & 20 & 24.4 & 50 & 25.0 \\
\hline $\begin{array}{l}46-55 \\
\text { yrs }\end{array}$ & 41 & 34.8 & 24 & 29.3 & 65 & 32.5 \\
\hline $\begin{array}{l}56-65 \\
\text { yrs }\end{array}$ & 31 & 26.3 & 26 & 31.7 & 57 & 28.5 \\
\hline $\begin{array}{l}66-75 \\
\text { yrs }\end{array}$ & 07 & 05.9 & 06 & 07.3 & 13 & 06.5 \\
\hline $\begin{array}{l}>75 \\
\text { yrs }\end{array}$ & 02 & 01.7 & 01 & 01.2 & 03 & 01.5 \\
\hline Total & 118 & 100.0 & 82 & 100.0 & 200 & 100.0 \\
\hline
\end{tabular}

\begin{tabular}{lcccccc} 
Table 2: Thyroid status of study subjects \\
\cline { 2 - 3 } \cline { 5 - 6 } Thyroid Status & \multicolumn{3}{c}{ Sex } & & \multicolumn{2}{c}{ Total } \\
\cline { 2 - 3 } \cline { 5 - 6 } & Female & Male & & Count & Percentage \\
\hline Normal & 77 & 66 & & 143 & 71.5 \\
Subclinical & 26 & 11 & & 37 & 18.5 \\
$\begin{array}{l}\text { Hypothyroidism } \\
\text { Hypothyroidism }\end{array}$ & 13 & 04 & & 17 & 8.5 \\
$\begin{array}{l}\text { Subclinical } \\
\text { Hyperthyroidism }\end{array}$ & 01 & 01 & & 2 & 1.0 \\
$\begin{array}{l}\text { Hyperthyroidism } \\
\text { Total }\end{array}$ & 01 & 00 & & 1 & 0.5 \\
\hline
\end{tabular}

\begin{tabular}{|c|c|c|c|c|}
\hline \multirow[t]{3}{*}{ Thyroid Status } & \multirow{2}{*}{\multicolumn{3}{|c|}{$\begin{array}{c}\text { Metabolic Syndrome Criteria } \\
\text { Criteria Present }\end{array}$}} & \multirow[t]{3}{*}{ Total } \\
\hline & & & & \\
\hline & 3 & 4 & 5 & \\
\hline Normal & 97 & 41 & 5 & 143 \\
\hline $\begin{array}{l}\text { Subclinical } \\
\text { Hypothyroidism }\end{array}$ & \multicolumn{3}{|c|}{ Hypothyroidism } & 37 \\
\hline Hypothyroidism & 9 & 8 & 0 & 17 \\
\hline $\begin{array}{l}\text { Subclinical } \\
\text { Hyperthyroidism }\end{array}$ & 2 & 0 & 0 & 2 \\
\hline Hyperthyroidism & 1 & 0 & 0 & 1 \\
\hline Total & 125 & 67 & 8 & 200 \\
\hline
\end{tabular}

predominantly affecting women. $59 \%$ of patients were females and $41 \%$ were males, which was consistent with findings of other studies. ${ }^{8} 9$ In our study average age of patients was $51.55+10.73$ years. Thirty-two and half percent $(\mathrm{n}=65)$ of patients came under the age group of $45-55$ years and $28.5 \%(n=57)$ of patients came under the age group 55-65 years. These findings were very similar to Ghanshyam P, S Shantha et al., ${ }^{8}$ and Saroj, Santhosh Kumar et al. ${ }^{9}$ In these studies maximum number of patients were in $4^{\text {th }}$ and $5^{\text {th }}$ decade. In this study, $4 \%$ of patients fulfilled all 5 metabolic syndrome criteria. Sixty-three and half percent fulfilled 3 out of 5 and $32.5 \%$ fulfilled 4 out of 5 criteria. In the study done by Chakradhar M, Chakravarthy et al., all criteria were present for $19.5 \%, 4$ criteria positive for $47.7 \%$ and 3 criteria positive for $32.8 \% .{ }^{10}$ Most of the patients in this study fulfilled 3 or 4 criteria of metabolic syndrome. In the present study, average value of waist circumference was $95.47+3.11$. This was very similar to study done by Saroj, Santhosh Kumar et al., ${ }^{9}$ with values WC was 102.5+6.7. In the study done by Deshmukh et al., WC was $98.6+9.7 . .^{11}$

In present study prevalence of thyroid dysfunction in metabolic syndrome was 28.5. In a study done by Uzunlulu et al., in Japan, prevalence of thyroid dysfunction was $16.4 \%$ in metabolic syndrome patients. ${ }^{12}$ In a study from Nepal, prevalence was $21.1 \% .{ }^{13}$ In studies like Ghanshyam PS Shantha et al., ${ }^{8}$ and P Gyawali et al., ${ }^{14}$ prevalence of thyroid dysfunction was $29.3 \%$ and $31.25 \%$ respectively. Prevalence of thyroid dysfunction in present study $(28.5 \%)$ was similar to study done by Ghanshyam PS Shantha et al. ${ }^{8}$ Prevalence of subclinical hypothyroidism was $18.5 \%$, overt hypothyroidism was $8.5 \%$ and subclinical hyperthyroidism was $1 \%$ in our study, which was similar to Ghanshyam PS Shantha et al., ${ }^{8}$ study. In Gyawali P et al., study, prevalence of subclinical hypothyroidism and overt hypothyroidism was $28.9 \%$ and $1.55 \%$ respectively. ${ }^{14}$ It was observed that there is high prevalence of thyroid dysfunction in the patients of metabolic syndrome. The prevalence of thyroid dysfunction was more among the females with metabolic syndrome than those among male subjects, which was consistent with studies like Gyawali P et al., ${ }^{14}$ and Saroj, Santhosh Kumar et al. ${ }^{9}$

\section{Limitations of the study}

The present study has some limitations. The sample size was small. Nutrition status of iodine and thyroid autoimmunity in the study patients was not assessed.

\section{CONCLUSION}

Patients of Metabolic Syndrome found to have high prevalence of thyroid dysfunction. Prevalence of subclinical hypothyroidism and overt hypothyroidism is higher than that of general population. Metabolic syndrome and Hypothyroidism are independent risk factor for Obesity and atherosclerotic diseases. It is possible that patients suffering from both of these entities have a compound risk. Therefore it is needed to screen such metabolic syndrome patients for the presence of thyroid dysfunction. It should be aggressively detected and treated in these patients for better outcome. 


\section{REFERENCES}

1. Reaven GM. Banting lecture 1998. Role of insulin resistance in human disease. Diabetes. 1988; 37:1595-1607.

https://doi.org/10.1016/S0899-9007 (96) 00380-2

2. Reaven GM. Insulin resistance, cardiovascular disease, and the metabolic syndrome: how well do the emperor's clothes fit? Diabetes Care. 2004; 27(4): 1011-1012.

https://doi.org/10.2337/diacare.27.4.1011

3. Eckel RH, Grundy SM and Zimmet PZ. The metabolic syndrome. Lancet. 2005; 365(9468): 1415-1428.

https://doi.org/10.1016/S0140-6736(05)66378-7

4. Klein I and Ojamaa K. Thyroid hormone and the cardiovascular system. N Engl J Med. 2001; 344(7): 501-509. https://doi.org/10.1056/NEJM200102153440707

5. Duntas LH. Thyroid disease and lipids. Thyroid. 2002; 12(4): 287-293.

https://doi.org/10.1089/10507250252949405

6. Dillmann WH. Mechanism of action of thyroid hormones. Med Clin North Am. 1985; 69(5): 849-861.

https://doi.org/10.1016/s0025-7125(16)30993-2

7. Expert Panel on Detection, Evaluation and Treatment of High Blood Cholesterol in Adults. Executive Summary of The Third Report of The National Cholesterol Education Program (NCEP) Expert Panel on Detection, Evaluation, And Treatment of High Blood Cholesterol In Adults (Adult Treatment Panel III). JAMA.2001; 285(19): 2486-2497. https://doi.org/10.1001/jama.285.19.2486

8. Ghanshyam P, Subash S, Anita A and Kumar V. Association between primary hypothyroidism and metabolic syndrome and the role of $\mathrm{C}$ reactive protein: a cross- sectional study from South India. Thyroid Research. 2009; 2(2): 1-7.

https://doi.org/10.1186/1756-6614-2-2

9. Khatiwada S, Sah SK, Kc R, Baral N and Lamsal M. Thyroid dysfunction in metabolic syndrome patients and its relationship with components of metabolic syndrome. Clin Diabetes Endocrinol. 2016; 2:3

https://doi.org/10.1186/s40842-016-0021-0

10. Chakradhar M, Chakravarthy DJK, Dorapudi BSCH, Deedi KM and Prasad BN. Thyroid dysfunction in metabolic syndrome patients in a tertiary care hospital. J Evolution Med Dent Sci. 2020; 9(30): 2103-2108.

https://doi: 10.14260/jemds/2020/459

11. Deshmukh V, Farishta $F$ and Bhole $M$. Thyroid dysfunction in patients with metabolic syndrome and its relationship with components of metabolic syndrome, pan- India study. Int J Endocrinol. 2018; 1-6. https://doi.org/10.1155/2018/2930251

12. Uzunlulu M, Yorulmaz E and Oguz A. Prevalence of subclinical hypothyroidism in patients with metabolic syndrome. Endocr J. 2007;54:71-76. https://doi.org/10.1507/endocrj.K06-124

13. Shrestha S, Das BKL, Baral B and Chandra L. Association of metabolic syndrome and its components with thyroid dysfunction in females. Int J Diab Dev Ctries. 2007; 27:24- 26. https://doi.org/10.4103/0973-3930.34754

14. Gyawali P, Takanche JS, Shrestha RK, Bhattarai P, Khanal K, Risal $P$, et al. Pattern of thyroid dysfunction in patients with metabolic syndrome and its relationship with components of metabolic syndrome. Diabetes Metab J. 2015; 39(1): 66-73. https://doi.org/10.4093/dmj.2015.39.1.66

\section{Authors Contribution: \\ RG-Concept and design of the study, prepared first draft of manuscript; AKV-Interpreted the results; reviewed the literature and manuscript preparation; \\ SC-Concept, coordination, statistical analysis and interpretation, preparation of manuscript and revision of the manuscript}

Work attributed to:

Netaji Subhash Chandra Bose Medical College, Jabalpur, Madhya Pradesh, India, Pin: 482003

Orcid ID:

Dr Ritu Gupta- (i) https://orcid.org/0000-0003-4937-5412

Dr Akhil K Vijayan- (1) https://orcid.org/0000-0001-9127-0652

Dr Sushma Choudhary- (1) https://orcid.org/0000-0002-3724-758X

Source of Support: Nil, Conflict of Interest: None declared. 